\title{
Comida como obra de arte: da revolução futurista à nouvelle cuisine
}

\author{
Fabiano Dalla Bona*
}

Há gastronomia quando há permanente querela dos Antigos e dos Modernos, e quando há um público capaz, ao mesmo tempo por sua competência e suas riquezas, de arbitrar essa querela.

Jean-François Revel

Que razões existiriam para não considerarmos a cozinha como uma expressão artística e o material alimentar num processo estético? Seria negar a obra de Daniel Spoerri e seu restaurante de eat art e os banquetes futuristas de Marinetti e seus companheiros.

Os cozinheiros sempre foram artistas, pois ilustram a tese de que cozinhar, escolher alimentos, elaborar pratos, celebrar a gula, querer e definir um estilo para seus fogões é promover uma visão de mundo através de discursos enunciados de maneira plástica e nutritiva, estética e alimentar. ${ }^{\dagger}$

Os cozinheiros instalam de imediato a atividade culinária no campo das artes e no domínio da estética. Gastérea é a sua musa. A cozinha, porém, passou a ser considerada arte contemporânea, inscrita realmente nas Belas Artes, somente após as revoluções desacralizantes operadas por Marcel Duchamp (1887 - 1968). Taillevant (1310-1395) e Antonin Carême (1783 - 1833) também foram grandes artistas, artistas da cozinha, mas suas obras plástico-culinárias estavam inseridas num contexto onde a comida não era lida numa chave estética, de obra de arte. Duchamp criou a obra de arte efêmera, descartável, desacralizou objetos elevando-os à glória de obras primas. Vale lembrar, também, que a comida e a cozinha celebram todos os nossos cinco sentidos; e justamente o mais ligado a ela, o paladar - ou deveríamos chamar de gula? - foi aquele que o Ocidente mais fez (e faz)

\footnotetext{
* Fabiano Dalla Bona é doutorando Letras Neolatinas na Universidade Federal do Rio de Janeiro e atualmente atua como professor na Universidade Federal do Paraná.

†NFRAY, Michel. A razão gulosa: filosofia do gosto. Trad. Ana Maria Scherer. Rio de Janeiro: Rocco, 1999, p.166.
} 
questão de condenar. Por que podemos nos extasiar ao ouvir a Quinta de Beethoven, ou ao admirar as Ninféias de Monet, a Vênus de Milo ou o Cristo Redentor e nos é negado o prazer de gozar de um bom prato com trufas negras, foie-gras e uma taça de champanhe? Pelo simples fato de serem efêmeras? O efêmero deve ser reivindicado e não tolerado apenas.

O que as artes produzem, como também a cozinha, é o imaterial, que não pode ser fechado, circunscrito. A cozinha é uma arte do tempo: tempo de preparo, duração dos cozimentos, cores e formas desenvolvidas de maneira tridimensional. Ela utiliza volumes e materiais diferentes, exatamente como suas irmãs mais ricas: a arquitetura, a pintura, a escultura e a música.

Todas as operações realizadas na cozinham modificam significativamente a matéria. Desenformar, corar, assar, fritar, escaldar, dourar, grelhar, ferver, abafar, flambar, é agir sobre a questão do tempo. Cortar, picar, rasgar, amarrar, enfarinhar é agir no terreno da forma. Moer, furar, ligar, conservar é interferir nas texturas. Refogar, aferventar, condimentar, temperar, marinar é intervir no campo da cor, da luz. As operações culinárias se realizam exatamente como as artísticas, produzindo modificações sobre uma matéria prima em estado bruto, não trabalhada. ${ }^{\star}$ Um grão de trigo não é macarrão. Até chegar a esse estado, o primitivo grão foi trabalhado, modificado, recriado.

Numa criação de arte culinária, os cinco sentidos são solicitados em sua completude: o perfume das iguarias, sua consistência, seu sabor, sua impressão visual e seus rumores, internos ou externos. É uma arte sinestésica.

O Futurismo, entre os primeiros grandes Ismos do século $\mathrm{XX}$, imediatamente se distinguiu pela vontade, comum a todas as vanguardas históricas, de "revolucionar a arte per mudar a vida". Essa vontade envolve e absorve todos os âmbitos da criatividade: literatura, poesia, arte, arquitetura, moda, decoração, design, tipografia, artes decorativas, cinema, teatro, cinema, escultura, musica, urbanismo, publicidade, sexualidade e fotografia. Imaginemos, pois, se Marinetti poderia se deixar intimidar em acrescentar a comida e a cozinha, com todo o seu imaginário pertinente, nas amplas esferas de seu movimento "transformador". Tal passo, porém, lhe rendeu não poucas críticas também da parte de muitos companheiros que "consideravam tal divertissément gastronômico uma ridícula fanfarrice, indigna de um movimento que, na visão deles, deveria ter assumido posturas 'sérias', talvez mais próximas

\footnotetext{
ONFRAY, M. A razão... Op.cit., p. 170 .

${ }^{\S}$ SALARIS, Claudia. Cibo futurista: dalla cucina nell'arte all'arte in cucina. Roma: Editori Riuniti, 2000.
} 
aos humores dos novecentos, que não àquela veia intransigente que é a base comum das vanguardas. ${ }^{* *}$

Serão exatamente a irreverência, a ironia, a audácia, o paradoxo, a extrema criatividade, o entusiasmo, o humorismo, os pressupostos determinantes e de ruptura de todas as vanguardas, fatores esses aos quais o Futurismo não se subtraiu. Objetivo principal era o desejo de chocar, de agitar os ritmos sonolentos da burguesia passadista e de seus símbolos (obras de arte, museus, academias, etc.), despertando-a do torpor no qual parecia submersa, mesmo correndo o risco de exagerar nas provocações, nos desafios. Mas tudo era previsto, mesmo o arremesso de legumes e hortaliças no palco que, regularmente ocorria, no final das apresentações futuristas. Previstos e desejados os empurrões, as vaias, os duelos verdadeiros ou fingidos. Tudo fazia parte da lógica e das estratégias futuristas: vencer o conformismo, embelezar a vida, deixá-la luminosa e veloz, fazer vir à tona as forças do Novo e do Moderno para realizar aquele sonho criativo. E a comida e a cozinha entraram a todo o vapor no seu raio de ação, fizeram parte de um sonho, de Giacomo Balla (1871 - 1958) e de Fortunato Depero (1892 - 1960) de salvar a sociedade através da arte moderna, do gosto pelo moderno, pelo novo

O futurismo de Marinetti e de Fillìa, o teórico cozinheiro do movimento, dá uma função simbólica à comida. Marinetti queria que um prato fizesse sentido e que a sua ingestão se realizasse como algo longe de ser neutro. Em 1931, a vanguarda italiana apodera-se da cozinha e passa a tratá-la como objeto estético, inspirado na metafísica desenvolvida desde o Manifesto de 1909, texto fundador do Movimento. Para os futuristas, os objetos não se esgotavam no contorno aparente e seus aspectos se interpenetravam continuamente, ao mesmo tempo ou vários tempos num só espaço. Procurava-se expressar o movimento real, registrando a velocidade descrita pelas figuras em movimento no espaço.

O Futurismo levou o projeto gastronômico italiano ao seu momento de maior efervescência. Para Marinetti, a questão alimentar era um meio de realizar um homem novo, integrante de uma nova civilização, com aspirações novas, aberto às perspectivas de uma cultura enérgica, veloz, cheia de vitalidade e de saúde.

A abolição da pastasciutta, absurda religião gastronômica italiana. Talvez o peixe seco, o roast-beef e o pudim agrade aos ingleses, aos holandeses a carne cozida com queijo, aos alemães o sauer-kraut, o toucinho defumado e a salsicha; mas aos italianos a pastasciutta não agrada. Por exemplo, contraposta com o espírito vivaz e com a alma apaixonada generosa intuitiva

\footnotetext{
** SALARIS, Claudia. Cibo futurista..., op. cit.p 123.
} 
dos napolitanos. Esses foram combatentes heróicos, artistas inspirados, advogados argutos, agricultores tenazes a despeito da volumosa pastasciutta cotidiana. Ao comê-la eles desenvolveram o típico ceticismo irônico e sentimental que tronca, em geral, o seu entusiasmo.

Um inteligentíssimo professor napolitano, o doutor Signorelli escreve: "A diferença do pão e do arroz, a pastasciutta é um alimento que se engole, não se mastiga. Esse alimento amidáceo é em grande parte digerido na boca pela saliva, e o trabalho de transformação é desempenhado pelo pâncreas e pelo fígado. Isso leva a um desequilíbrio com o distúrbio desses órgãos. Disso deriva: fraqueza, pessimismo, inatividade nostálgica e neutralismo". ${ }^{\dagger}$

Não obstante a exuberância de suas propostas, em geral pouco factíveis num contexto quotidiano, a cozinha futurista prenunciou as modificações do gosto em muitos aspectos. A atenção e a pesquisa em direção a uma absoluta originalidade das iguarias, bem descrita em seus nomes fantásticos, encontram na cozinha futurista um lugar de destaque com combinações imprevisíveis, com a utilização de elementos exóticos e raros: carne de camelo e pétalas de rosa, os doce-salgados como tâmaras e anchovas, peixe com banana e abacaxi, carne e mel, pasta de amêndoas e pimenta calabresa picante. As atenções ao aspecto visual, pictórico e escultórico dos pratos e da arrumação das mesas, deveriam fazer que cada iguariaescultura tivesse de ter uma arquitetura original, e se possível, diferente para cada um dos comensais. Para criar um homem novo e agressivo, os futuristas deram poderes arquitetônicos à cozinha, e pediram aos seus cozinheiros que criassem pratos capazes de dar a todos "a impressão de comer obras de arte", produções conceituais e significantes, integrantes de um mundo verbal, plástico e sinestésico. Aeropintores, aeropoetas, aeroceramistas, palavristas, críticos de arte e até engenheiros foram convidados a criar aerovivandas e aerobebidas, expressões novas desse novo conceito alimentar. $\mathrm{O}$ conjunto de uma iguaria deveria fornecer vigor e força, o espírito deveria permanecer livre num corpo liberto do peso das massas alimentares, dos molhos e dos cremes farinhentos. As receitas deveriam romper absolutamente com o passado e destruí-lo completamente.

A cerimônia culinária futurista mirava um hedonismo global onde todo o corpo fosse celebrado: as dimensões sensuais, afetivas e emotivas. Durante um jantar, uma voz em off anunciava o título poético dos pratos à assistência que a seguir era submetida a uma musica composta de trechos de composições de Bach e barulho de motores. A cada serviço, garçons vaporizavam essências aromáticas e perfumes variados que conotavam o prato a ser servido posteriormente. O perfume era disperso por ventiladores, pela força de seus motores. $\mathrm{O}$ tato era convocado por um objeto retangular que se encontrava sobre a mesa: uma superfície

\footnotetext{
$\pitchfork$ Trecho do Manifesto da Cozinha Futurista. Tradução nossa.
} 
dividida em três partes iguais de lixa, veludo e seda. Os comensais roçavam o indicador e o dedo médio da mão esquerda sobre a superfície, enquanto se serviam dos pratos, com a mão direita. Os talheres foram banidos das mesas futuristas. Seu templo era o Santopalato, primeiro restaurante futurista, inaugurado em Turim, em 8 de março de 1931.

Para os praticantes de sua cozinha, a alimentação ingerida era um conceito menos dietético que simbólico. A arte visava a investigação da matéria no terreno da leveza, do dinamismo, da energia, da alegria de viver e da saúde.

A pastasciutta, nutritivamente inferior de $40 \%$ em relação à carne, ao peixe, aos legumes, amarra os italianos de hoje com os seus nós aos lentos teares de Penélope e aos sonolentos veleiros à procura de vento. Por que ainda opor o seu pesado bloqueio à imensa rede de ondas curtas e longas que o gênio italiano lançou sobre os oceanos e continentes, e às paisagens de cor forma rumor que a televisão faz navegar ao redor da terra? Os defensores da pastasciutta carregam o seu peso ou a sua ruína no estômago, como ergastolários ou arqueólogos. Lembrai-vos, pois, que a abolição da pastasciutta libertará a Itália do custoso trigo estrangeiro e favorecerá a indústria italiana do arroz.

$\mathrm{O}$ artista era o escultor, o pintor, o artífice dessa energia, e se era cozinheiro, essa energia tornava-se assimilável pelo homem através de sua alimentação. As receitas eram sempre assinadas, autorais como se diria hoje. Sua escrita era semelhante à escrita dos livros de receita pré-era burguesa: nelas não eram especificadas as quantidades mensuráveis dos ingredientes. A tirania das medidas era esquecida em favor da criatividade de seus criadores, e os pratos deveriam permitir emoções violentas, carregadas de força selvagem de seus sabores, mas ao mesmo tempo, repletas de graça e leveza.

A abolição das tradicionais misturas para o experimento de todas as novas misturas aparentemente absurdas, segundo os conselhos de Jarro, Maincave e outros cozinheiros futuristas. ${ }^{\S \S}$

Outra grande inovação da estética culinária futurista foi a introdução da tecnologia na cozinha. As máquinas completavam o ideal do manifesto que dizia:

Cantaremos as grandes multidões agitadas pelo trabalho, pelo prazer ou pela revolta; cantaremos o vibrante fervor noturno dos arsenais e dos estaleiros incendiados por violentas luas elétricas; as gulosas estações de trem engolindo serpentes fumegantes; as fábricas suspensas das nuvens pelas fitas do seu fumo; as pontes que saltam como atletas por sobre a diabólica cutelaria dos rios ensolarados; os aventureiros navios a vapor que farejam o

\footnotetext{
Trecho do Manifesto da Cozinha Futurista. Tradução nossa.

$\S \S$ Idem.
} 
horizonte; as locomotivas de vasto peito, galgando os carris como grandes cavalos de ferro curvados por longos tubos e o deslizante vôo dos aviões cujos motores drapejam ao vento como o aplauso de uma multidão entusiástica. $^{* * *}$

Ozonizadores, lâmpadas ultravioleta, eletrolisadores, moinhos coloidais, destiladores, autoclaves, centrífugas e dialisadores passam a integrar a lista dos novos utensílios da cozinha:

Uma dotação de instrumentos científicos na cozinha: ozonizadores que atribuam o perfume do ozônio aos líquidos e iguarias, lâmpadas para emissão de raios ultravioleta (visto que muitas substâncias alimentícias irradiadas com raios ultravioleta adquirem propriedades ativas, tornam-se mais assimiláveis, impedem o raquitismo nas crianças, etc.), eletrolizadores para decompor sucos extratos etc, de modo a obter de um produto conhecido um novo produto com novas propriedade, moinhos coloidais para possibilitar a pulverização das farinhas, fruta seca, drogas, etc, aparelhos de destilação à pressão normal e a vácuo, autoclaves centrífugas, dialisadores. O uso desses aparelhos deverá ser científico, evitando, por exemplo, o erro de cozinhar as iguarias em panelas de pressão a vapor, o que provoca a destruição das substâncias ativas (vitaminas, etc.) por causa das altas temperaturas. Os indicadores químicos indicarão a acidez, a basicidade dos molhos e servirão para corrigir eventuais erros: falta de sal, excesso de vinagre, excesso de pimenta, excesso de doce.

Muitos dos elementos das renovações gastronômicas futuristas seja do ponto de vista estético que do tratamento da matéria, foram assimilados entre os anos sessenta e setenta pela Nouvelle cuisine, come evidencia Claudia Salaris. ${ }^{\dagger \dagger}$

Em 1972, Henri Gault e Christian Millau, dois jornalistas franceses especializados em gastronomia cunharam o termo nouvelle cuisine para definir o estilo culinário de um grupo de chefs de talento formado pelos irmãos Troisgros, Paul Bocuse, Michel Guérard que, desde o inicio dos anos sessenta havia entrado em conflito com a tradição da haute cuisine française. O momento mais importante da elaboração gastronômica não era mais a perfeita aplicação das regras, mas sim a criatividade, a capacidade de combinar elementos pouco usuais para obter novas sensações e novas harmonias, como as típicas combinações de frutas com carne ou peixes, os novos aromas e os sabores doce-salgados e agridoces.

Segundo esses novos princípios, a cozinha deve respeitar a sazonalidade e o frescor dos produtos, adequar-se ao mercado e aos novos ritmos da vida reduzindo, ao mínimo, as elaborações e as super-estruturas tais como temperos fortes e molhos pesados. Em antítese à cozinha clássica, a nouvelle cuisine afirma-se através do respeito a simplicidade dos sabores, a exaltação do gosto e das cores originais dos ingredientes utilizados. Decorre de tudo isso uma

*** O primeiro manifesto futurista. Disponível em: http://viriatos.blogspot.com/2003/09/o-primeiro-manifestofuturista.html. Acesso em: 10/10/2007.

SALARIS, Claudia. Marinetti: arte e vita futurista. Roma: Editori Riuniti, 1997. 
valorização da identidade sensorial dos ingredientes fazendo chegar ao palato as diferenças naturais das matérias-primas utilizadas. A redução da manipulação da maeria, metodologias de cozimento mais naturais, cozimentos breves, cozimento de ingredientes separadamente e, inclusive, os peixes e carnes cruas, de derivação tipicamente japonesa, visam respeitar a identidade natural dos produtos.

Além disso, como na cozinha futurista, também a nouvelle cuisine reserva uma atenção à apresentação da comida, e um amor particular pelo detalhe no refinamento da composição, da cor e da forma das iguarias, cujas arquiteturas são pensadas como obras de arte visual. Afirma-se o uso dos pratos individuais de grandes dimensões em substituição aos normais pratos de serviço, sobre os quais são apresentadas combinações de pequenas quantidades de comida, numa organização compositiva que reconduz à estética oriental, principalmente japonesa.

Os pratos de porcelana são geralmente brancos, sem nenhuma decoração, de modo que elas não interfiram na composição cromática da comida. O prato branco nada mais é que a tela sobre a qual o cozinheiro-artista pode criar a sua obra, que será emoldurada pelas largas bordas desse prato branco.

A miniaturização da porção, a rarefação da comida sobre o prato, a exibição de espaços em branco, se inserem nos modos de expressão do minimalismo gastronômico, assim como a minimal art, naqueles mesmos anos sessenta, contrapunha a opulência policromática do contexto urbano e dos meios de comunicação de massa com soluções formais mínimas e essenciais, reduzindo a obra a estruturas simples e ao uso das cores primárias.

$\mathrm{Na}$ base das analogias entre a cozinha futurista e a nouvelle cuisine reside um diferente tratamento da matéria com relação à tradição do passado, e um diferente papel da receita. Ambas as escolas investem na valorização dos ingredientes, crus ou pouco elaborados, e pregam um processo de naturalização em oposição à transformação cultural da comida atuada através do cozimento e da combinação de elementos variados.

Do ponto de vista estético, a nouvelle cuisine retoma o estilo minimalista japonês, como já acenado, no jogo de cheios e vazios, na assimetria, na espontaneidade e no respeito pelos elementos naturais. O estado cru dos materiais de derivação japonesa, adquire um estatuto estético essencialmente visual. ${ }^{\S \S}$

\footnotetext{
LÉVI-STRAUSS, Claude. O cru e o cozido. Trad. Beatriz Perrone Moisés. São Paulo: Cosac Naify, 2004.

$\S \S \S$ BARTHES, Roland. L'impero dei segni. Torino: Einaudi, 1984.
} 
Sobre isso nos fala um dos expoente máximos da culinária italiana, Gualtiero Marchesi:

A differenza della cucina classica, che s'identificava in un corpus di ricette rigorosamente codificato, la nuova è per eccellenza una cucina "senza spartito", in cui l'adozione di un piatto prevede sempre una sorta d'arrangiamento personale. In alta ristorazione il gesto creativo del cuoco diventa esplicito: il proscenio conviviale si trasforma in uno spettacolo squisitamente individualistico, in cui si moltiplicano i solisti-compositori [la cucina come il jazz]. Tant'è che, mentre le cucine del passato contenevano in sé un progetto di riproducibilità, nella moderna "cucina d'autore" il facsimile, quando sia riconosciuto come tale, viene vissuto alla stregua di un plagio. Più che stabilire un copione valido una volta per tutte, la nuova cucina impartisce dunque una lezione di metodo.***

A análise ate aqui conduzida obriga, portanto, a inverter o ponto de partida: a cozinha não é mais alográfica, mas autográfica. Para entender como esse deslocamento de uma para outra categoria ocorreu, parece indispensável estabelecer um paralelo com as linguagens artísticas tradicionais, pois é exatamente com o confronto e a contaminação dessas particulares formas de expressão que ocorreu tal transformação.

O nó da questão é o papel e o valor do texto e do autor. Enquanto na cozinha tradicional o texto se configura como um conjunto impessoal de "instruções", na cozinha futurista e na nouvelle cuisine, e nas mais recentes contaminações da arte com a cozinha, o texto não existe mais como um sistema estruturado por regras para a execução de uma obra, mas sim numa obra em construção, num lugar de improvisação. O autor de um texto desse gênero emerge com grande evidencia manifestando-se como um executor. O texto-receita, portanto, é móvel e mutante, no interior de um quadro delimitado por seu autor-executor.

Da mesma forma que a improvisação musical supera a natureza de arte alográfica da musica, assim a cozinha autoral, tanto a futurista como a nouvelle cuisine, adquire um status de obra autobiográfica enquanto torna-se significativa a distinção entre original e falso. As receitas futuristas quase nunca são escritas utilizando o imperativo, como acontece normalmente com outras receitas, mas em terceira pessoa impessoal e com o infinitivo, como se descrevessem uma obra completa e não um passo-a-passo para a sua execução. A receitaprato transforma-se em obra daquele autor.

Através da contaminação com o mundo da arte, o Futurismo, a cozinha muda o estatuto e o valor do texto (receita) e do autor (cozinheiro, chef). Se na cozinha tradicional o texto é impessoal, na cozinha futurista e na nouvelle cuisine, emerge com clareza a

\footnotetext{
${ }^{* * * * *}$ MARCHESI, Gualtiero. La tavola imbandita: storia estetica della cucina. Roma-Bari: Laterza, 2001, p.154.
} 
centralidade do papel do autor que produz um texto verbal (a receita) e material (o prato), onde imprime uma marca de originalidade que o torna irrepetível e irreproduzível como um quadro. 